\title{
Ginsenoside F4 inhibits platelet aggregation and thrombus formation by dephosphorylation of $\mathrm{IP}_{\mathbf{3}} \mathrm{RI}$ and VASP
}

\author{
Jung-Hae Shin ${ }^{1}$ Hyuk-Woo Kwon ${ }^{1} \cdot$ Dong-Ha Lee L,3 $^{2,3}$ \\ Received: 11 January 2019 / Accepted: 11 February 2019 / Published Online: 31 March 2019 \\ (C) The Korean Society for Applied Biological Chemistry 2019
}

\begin{abstract}
The root of Panax ginseng is used in ethnomedicine throughout eastern Asia and various recent studies have proved that Panax ginseng has inhibitory effects on cardiovascular disease. Each factor causing cardiovascular disease is known to have a very complex process which is achieved by a diverse number of mechanisms. Among these factors, platelets are the most important because they directly participate in thrombogenesis. Therefore, inhibiting the activity of platelets is an essential element for prevention of cardiovascular diseases. Our previous study showed the antiplatelet effects of Korean red ginseng extract and two of its components, ginsenoside $\operatorname{Rg} 3$ and ginsenoside Ro. However, the inhibitory mechanism of other ginsenosides remains unclear. Therefore, we investigated the inhibitory mechanism of ginsenoside F4 (G-F4) from Korean red ginseng on the regulation of signaling molecules involved in human platelet aggregation. With the use of G-F4, collagen-induced human platelet aggregation was inhibited in a dose-dependent manner, and it suppressed collagen-induced elevation of $\left[\mathrm{Ca}^{2+}\right]_{\mathrm{i}}$ mobilization through elevated phosphorylation of inositol 1, 4, 5-triphosphate receptor I $\left(\mathrm{Ser}^{1756}\right)$. In addition, GF4 inhibited fibrinogen binding to $\alpha \mathrm{IIb} / \beta_{3}$ during collageninduced human platelet aggregation. Thus, in the present study, GF4 showed an inhibitory effect on human platelet activation,
\end{abstract}

Jung-Hae Shin and Hyuk-Woo Kwon contributed equally to this work.

Dong-Ha Lee $(\bowtie)$

E-mail: dhlee@nsu.ac.kr

${ }^{1}$ Department of Biomedical Laboratory Science, Far East University, Eumseong 27601, Republic of Korea

${ }^{2}$ Department of Biomedical Laboratory Science, Namseoul University, Cheonan 31020, Republic of Korea

${ }^{3}$ Molecular Diagnostics Research Institute, Namseoul University, Cheonan 31020, Republic of Korea

This is an Open Access article distributed under the terms of the Creative Commons Attribution Non-Commercial License (http://creativecommons. org/licenses/by-nc/3.0/) which permits unrestricted non-commercial use, distribution, and reproduction in any medium, provided the original work is properly cited. suggesting its potential use as a new natural medicine for preventing platelet-mediated cardiovascular diseases.

Keywords Clot retraction - Ginsenoside F4 - Inositol 1, 4, 5triphosphate receptor I $\left(\operatorname{Ser}^{1756}\right) \cdot$ Vasodilator-stimulated phosphoprotein $\left(\operatorname{Ser}^{157}\right)$

\section{Introduction}

An area of damaged vascular wall activates platelets through a series of physiological molecules, such as ADP, thrombin, and collagen. Platelet aggregation is essential for the maintenance of normal hemostasis, but it can also cause thrombosis at the same time. The production of thrombosis is a critical factor for patients and people who have risks for cardiovascular disease. Therefore, drugs that can inhibit the activity of platelets are needed [1]. However, despite numerous investigations into the discovery and development of more effective antiplatelet and antithrombotic drugs, the effect of these drugs on mortality rates is still weak. In addition, some drugs can lead to serious complications [2]. Therefore, further research is needed for the development of more effective and safer drugs to ensure better treatment and prevention of cardiovascular disease.

Platelet activation and aggregation are due to the activation of intracellular calcium and integrin glycoprotein IIb/IIIa $\left(\alpha \mathrm{IIb} / \beta_{3}\right)$. Intracellular $\mathrm{Ca}^{2+}\left(\left[\mathrm{Ca}^{2+}\right]_{\mathrm{i}}\right)$ is a platelet aggregation-inducing molecule, and influences activation of aggregation associated molecules. The increased $\left[\mathrm{Ca}^{2+}\right]_{\mathrm{i}}$ activates the $\mathrm{Ca}^{2+} /$ calmodulin-dependent phosphorylation of the myosin light chain to trigger the inside-out signaling pathway leading to platelet activation. Activated platelets affect the structural change of $\alpha \mathrm{Ilb} / \beta_{3}$ on the platelet surface, which allows for interaction with its plasma ligands (i.e. fibrinogen, fibronectin, and vitronectin), causing activation of the outside-in signaling pathway, and thrombus formation $[3,4]$.

Elevation in $\left[\mathrm{Ca}^{2+}\right]_{\mathrm{i}}$ level by agonists is dependent on its 
mobilization from the endoplasmic reticulum and influx from extracellular spaces. Thrombin, a platelet agonist, is known to bind to the Gq-coupled proteinase-activated receptor and activate phospholipase $\mathrm{C}_{\beta}\left(\mathrm{PLC}_{\beta}\right)$, stimulating the aggregation of platelets. The activated $\mathrm{PLC}_{\beta}$ hydrolyzes phosphatidylinositol 4, 5bisphosphate $\left(\mathrm{PIP}_{2}\right)$ into diacylglycerol and inositol 1, 4, 5trisphosphate $\left(\mathrm{IP}_{3}\right)$ [5]. $\mathrm{IP}_{3}$ mobilizes free cytosolic $\mathrm{Ca}^{2+}$ from the endoplasmic reticulum by binding to $\mathrm{IP}_{3}$ receptor type $\mathrm{I}\left(\mathrm{IP}_{3} \mathrm{RI}\right)$. The increased $\mathrm{Ca}^{2+}$ stimulates granule secretion and platelet aggregation. Another way to increase $\left[\mathrm{Ca}^{2+}\right]_{\mathrm{i}}$ level is through an influx of $\mathrm{Ca}^{2+}$ from extracellular spaces. Depletion of the intracellular $\mathrm{Ca}^{2+}$ store by $\mathrm{IP}_{3}$ is known to be associated with the influx of extracellular $\mathrm{Ca}^{2+}$ [6].

During normal circulation, nitric oxide and prostaglandin $\mathrm{I}_{2}$ are both released by vascular endothelial cells facilitating the production of cyclic guanosine monophosphate (cGMP) and cyclic adenosine monophosphate (cAMP) in the platelets. Elevated cGMP and cAMP levels induce the activation of protein kinase $G(P K G)$ and protein kinase A (PKA), respectively. Both PKA and PKG then phosphorylate substrate protein inositol triphosphate receptor type I and vasodilator-stimulated phosphoprotein (VASP) [7]. IP ${ }_{3} \mathrm{RI}$ becomes inactive after phosphorylation, leading to inhibition of $\left[\mathrm{Ca}^{2+}\right]_{\mathrm{i}}$ mobilization $[8,9]$. In the platelet, a major substrate of PKA and PKG is vasodilator-stimulated phosphoprotein and it supports the regulation of actin filament dynamics as well as $\alpha \mathrm{IIb} / \beta_{3}$ activation. However, the phosphorylation of VASP Ser ${ }^{157}$ counters these actions by suppressing $\alpha \mathrm{Ilb} / \beta_{3}$ activation and inhibiting actin filament elongation [10,11]. Therefore, the phosphorylation of $\mathrm{IP}_{3} \mathrm{RI}$ can be very useful for evaluating the $\mathrm{Ca}^{2+}$-antagonistic effect, whereas VASP phosphorylation is important for evaluating $\alpha \mathrm{IIb} / \beta_{3}$-inhibition effect.

Panax ginseng C.A. Meyer has been well known to induce various biological activities through a number of different ginsenosides. The ginsenosides are produced of different composition via the processing method. Ginsenoside Rb1, Rc, Rd, Re, and Rgl are major components of white and red ginseng, while unique ginsenoside constituents such as $\mathrm{Rg} 3, \mathrm{Rg} 5, \mathrm{Rk} 1$, and F4 are found specifically from red ginseng [12]. Ginsenoside F4 (G-F4) is a protopanaxatriol group which has two sugar residues, glucoserhamnose, connected with the position of carbon-6 (Fig. 1) $[12,13]$. It has been reported that G-F4 has an inhibitory effect on human lymphocytoma JK cells by inducing apoptosis [14], and it is able to block cartilage breakdown in rabbit cartilage tissue culture [15]. However, a study for the effect on platelets by G-F4 has yet to be investigated. Therefore, we characterized the modulatory mechanism of G-F4 on human platelet activation.

\section{Materials and Methods}

\section{Materials}

Ginsenoside F1, F2, and F4 (G-F1, G-F2, and G-F4) were

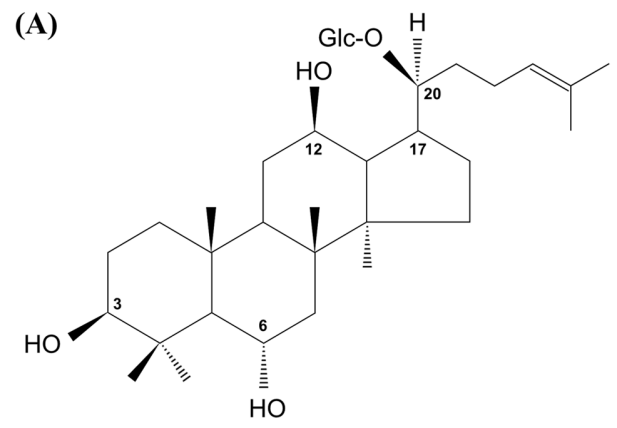

Ginsenoside F1

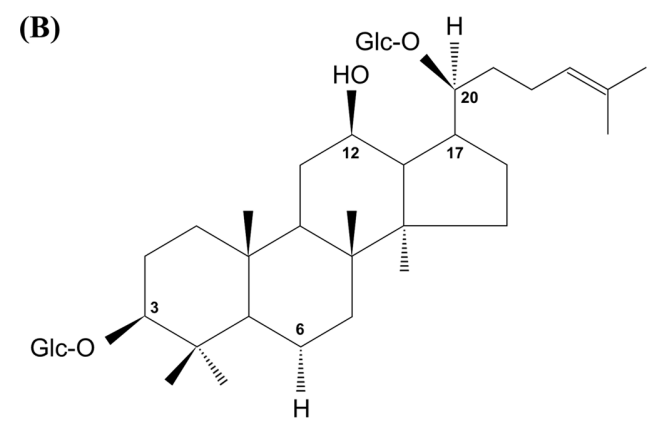

Ginsenoside F2

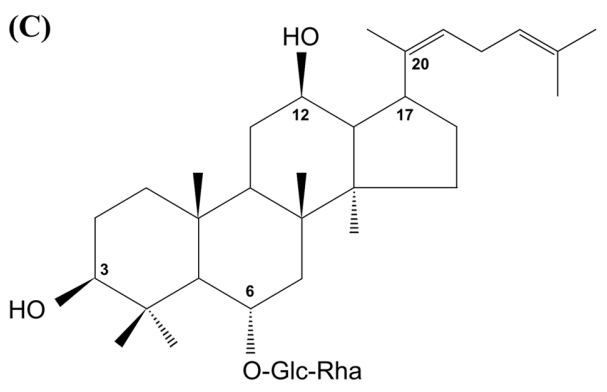

Ginsenoside F4

Fig. 1 Chemical structure of ginsenoside F1, F2 and F4. (A) Ginsenoside F1, a protopanaxatriol, isolated from the Korean Red Ginseng. (B) Ginsenoside F2, a protopanaxdiol, isolated from the Korean Red Ginseng. (C) Ginsenoside F4, a protopanaxatriol, isolated from the Korean Red Ginseng. Glc, glucose; Rha, rhamnose

obtained from the Ambo Institute (Daejeon, Korea). Chrono-Log Corporation (Havertown, PA, USA) provided the collagen. 2acetoxymethyl (Fura 2-AM) was obtained from Invitrogen (Eugene, OR, USA). Thapsigargin was obtained from Cayman Chemical (Ann Arbor, MI, USA). The lysis buffer, Anti-phosphorVASP $\left(\mathrm{Ser}^{157}\right)$, anti-phosphor-inositol-3-phosphate receptor type I $\left(\mathrm{Ser}^{1756}\right)$, anti- $\beta$-actin, and anti-rabbit IgG-HRP-conjugate were bought from Cell Signaling (Beverly, MA, USA). Polyvinylidene difluoride (PVDF) membrane and enhanced chemiluminescence solution (ECL) were purchased from General Electric Healthcare (Chalfont St. Giles, Buckinghamshire, UK). Invitrogen Molecular 


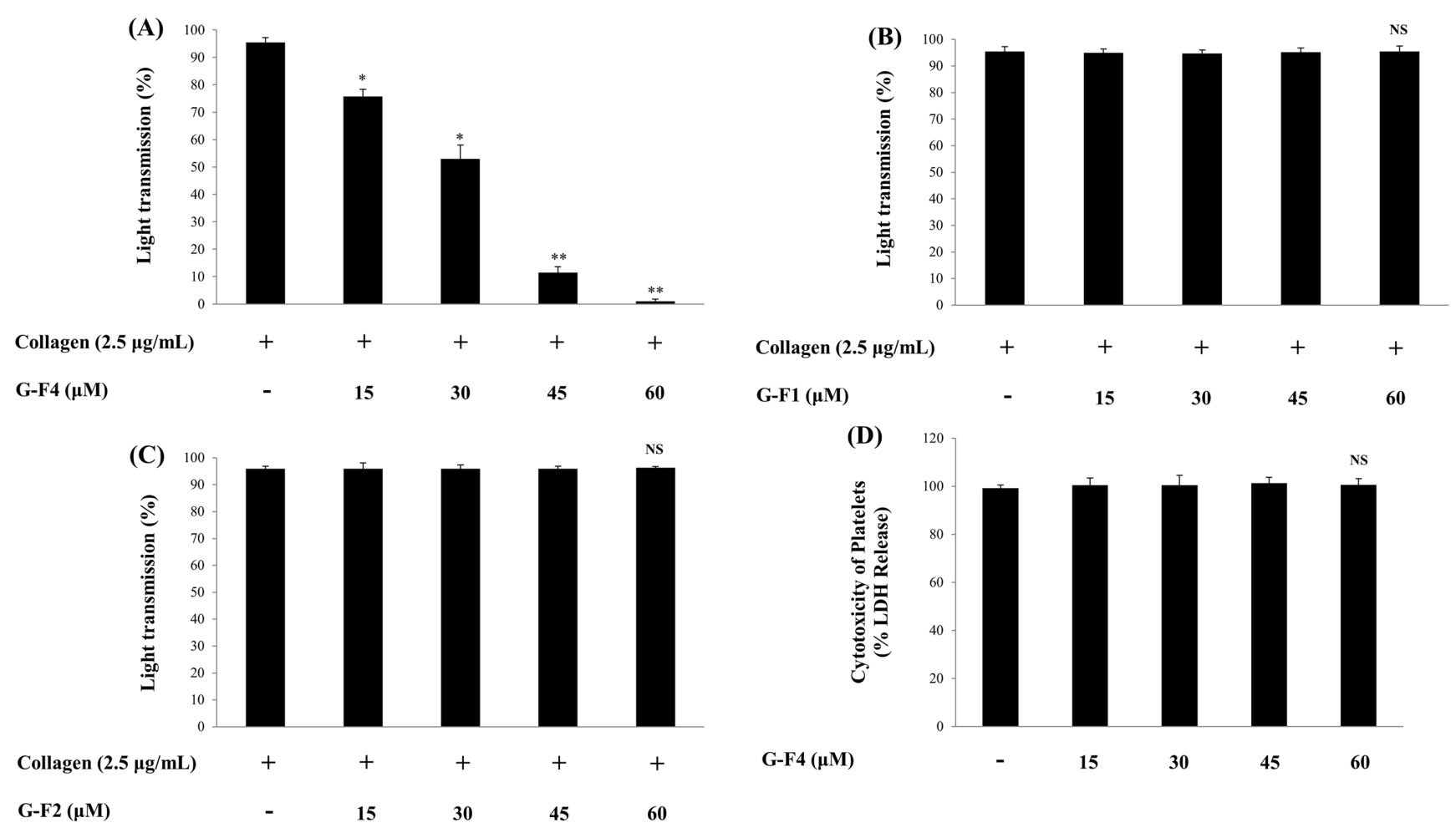

Fig. 2 Inhibitory effects of G-F1, F2 and F4 on collagen-induced human platelet aggregation. (A) Effects of G-F4 on collagen-induced human platelet aggregation. (B) Effects of G-F1 on collagen-induced human platelet aggregation. (C) Effects of G-F2 on collagen-induced human platelet aggregation. (D) Cytotoxicity of G-F4 on human platelets. Measurement of platelet aggregation was described in "Materials and Methods" section. The data are expressed as the mean \pm standard deviation $(\mathrm{n}=4) .{ }^{*} p<0.05,{ }^{* *} p<0.01$ versus the collagen-stimulated human platelets

Probes (Eugene, OR, USA) provided the Fibrinogen Alexa Fluor 488 conjugate.

\section{Preparation of washed human platelets}

The Korean Red Cross Blood Center (Changwon, Korea) provided the Human platelet-rich plasma (PRP). The plasma was centrifuged at $1,300 \times g$ for $10 \mathrm{~min}$. The platelet-containing pellet was then washed twice with washing buffer $(138 \mathrm{mM} \mathrm{NaCl}, 2.7$ $\mathrm{mM} \mathrm{KCl}, 12 \mathrm{mM} \mathrm{NaHCO} 3,0.36 \mathrm{mM} \mathrm{NaH}_{2} \mathrm{PO}_{4}, 5.5 \mathrm{mM}$ glucose, and $\left.1 \mathrm{mM} \mathrm{Na} \mathrm{NaDTA}_{2} \mathrm{pH} 6.5\right)$, and a suspension buffer (138 mM $\mathrm{NaCl}, 2.7 \mathrm{mM} \mathrm{KCl}, 12 \mathrm{mM} \mathrm{NaHCO}, 0.36 \mathrm{mM} \mathrm{NaH} \mathrm{PO}_{4}, 0.49$ $\mathrm{mM} \mathrm{MgCl}_{2}, 5.5 \mathrm{mM}$ glucose, $0.25 \%$ gelatin, $\mathrm{pH}$ 6.9) was then used to resuspend them. The final concentration of platelets was adjusted to $5 \times 10^{8} / \mathrm{mL}$. All aforementioned procedures were performed at $25{ }^{\circ} \mathrm{C}$. The Public Institutional Review Board at the National Institute for Bioethics Policy (Seoul, Korea) provided experimental approval (PIRB-).

\section{Platelet aggregation}

Platelets $\left(10^{8} / \mathrm{mL}\right)$ were preincubated in separate samples with or without G-F4 in $2 \mathrm{mM} \mathrm{CaCl}_{2}$ for $3 \mathrm{~min}$ at $37^{\circ} \mathrm{C}$. Thrombin $(0.05$ $\mathrm{U} / \mathrm{mL}$ ) was then added to stimulate. An aggregometer (ChronoLog Corporation) was used for 5 minutes to perform the platelet aggregation assay. An increase in light transmission was used to determine the platelet aggregation rate (\%). A solution of $0.1 \%$ dimethyl sulfoxide (DMSO) was used to dissolve the G-F4.

\section{Measurement of cytotoxicity}

Cytotoxicity was determined through the leakage of lactate dehydrogenase (LDH) from cytosol. Human washed platelets $\left(10^{8}\right.$ platelets $/ \mathrm{mL}$ ) were incubated for 2 hours at room temperature with various concentrations of substances and then centrifuged at room temperature for $2 \mathrm{~min}$ at $12,000 \mathrm{~g}$. The supernatant was measured by LDH assay kit (Cayman Chemical) at an optical density of $490 \mathrm{~nm}$.

\section{Intracellular calcium concentration and calcium influx}

PRP was incubated at $37^{\circ} \mathrm{C}$ for 60 min with $5 \mu \mathrm{M}$ of Fura 2-AM. The washed platelets $\left(10^{8} / \mathrm{mL}\right)$, loaded with Fura 2-AM, were prepared using the procedure described above, preincubated with $\mathrm{G}-\mathrm{F} 4$ for $3 \mathrm{~min}$ at $37{ }^{\circ} \mathrm{C}$ in the presence of $2 \mathrm{mM} \mathrm{CaCl}_{2}$. They were then stimulated with collagen $(2.5 \mu \mathrm{g} / \mathrm{mL})$ for intracellular calcium concentration $\left(\left[\mathrm{Ca}^{2+}\right]_{i}\right)$ and thapsigargin $(1 \mu \mathrm{M})$ for $\mathrm{Ca}^{2+}$ influx. After thapsigargin stimulation, $2 \mathrm{mM}$ of calcium was added at $3 \mathrm{~min}$. A spectrofluorometer (SFM-25; BioTek Instruments, Italy) was used to measure Fura 2-AM fluorescence. The excitation wavelength was set starting at $340 \mathrm{~nm}$ and changed every $0.5 \mathrm{~s}$ until reaching $380 \mathrm{~nm}$. An emission wavelength of $510 \mathrm{~nm}$ was 


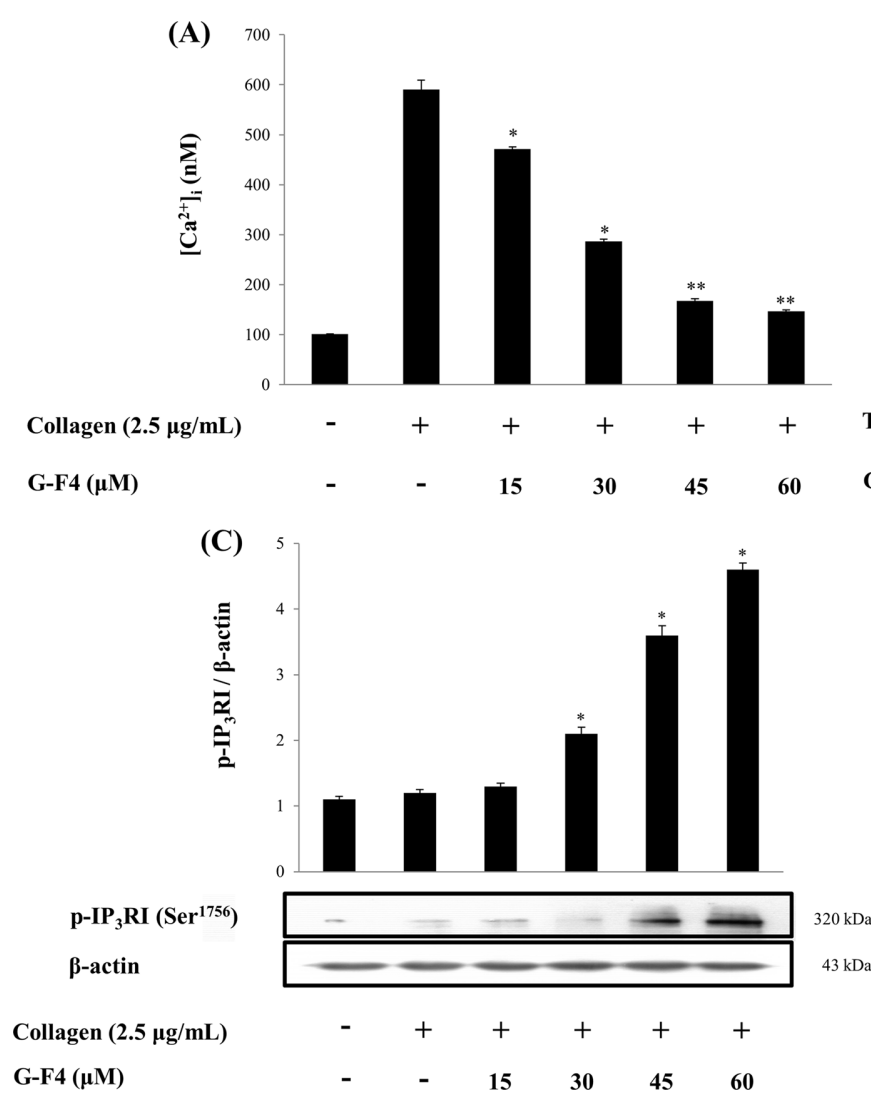

used. The Grynkiewicz method [16] was used to calculate the $\left[\mathrm{Ca}^{2+}\right]_{\mathrm{i}}$ values.

\section{Immunoblotting}

Platelet aggregation was terminated by addition of $1 \times$ lysis buffer. A BCA protein assay kit (Pierce Biotechnology, IL, USA) was used to measure the total protein concentration of the platelet lysates. Proteins $(15 \mu \mathrm{g})$ were separated through $8 \%$ SDS-PAGE, and transferred onto PVDF membranes. The primary and secondary antibodies were set at dilutions of 1:1,000 and 1:10,000, respectively. ECL reagent (General Electric Healthcare, Buckinghamshire, UK) was used to visualize protein bands.

\section{Fibrinogen binding to $\alpha \mathbf{I I} b / \beta_{3}$}

Using Alexa Flour 488-human fibrinogen $(30 \mu \mathrm{g} / \mathrm{mL})$, the platelet aggregation assay was conducted at $37{ }^{\circ} \mathrm{C}$ for $5 \mathrm{~min}$. To terminate the reaction, $0.5 \%$ paraformaldehyde in cold phosphate-buffered saline ( $\mathrm{pH}$ 7.4) was added. The aforementioned procedures were conducted in darkness. The fibrinogen binding assay was performed using flow cytometry (BD Biosciences, San Jose, CA, USA), and analyzed with the CellQuest software (BD Biosciences).

\section{Platelet-mediated fibrin clot retraction}

Human PRP $(500 \mu \mathrm{L})$ was transferred into a polyethylene tube to avoid adhesion, separate samples were preincubated with G-F4 $(45,60 \mu \mathrm{M})$ for $15 \mathrm{~min}$ at $37^{\circ} \mathrm{C}$ and stimulated with thrombin

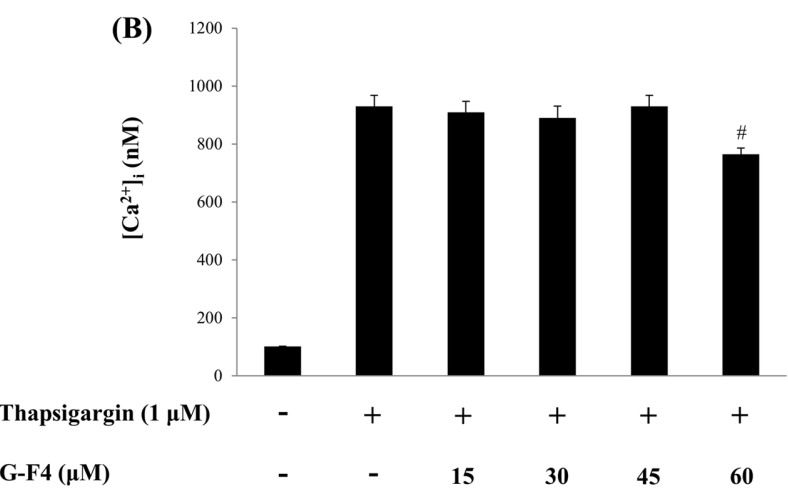

Fig. 3 Inhibitory effects of G-F4 on $\left[\mathrm{Ca}^{2+}\right]_{i}$ mobilization, influx and $\mathrm{IP}_{3} \mathrm{RI}$ phosphorylation. (A) Inhibitory effects of G-F4 on collagen-induced $\left[\mathrm{Ca}^{2+}\right]_{\mathrm{i}}$ mobilization. (B) Effects of G-F4 on thapsigargin-induced $\mathrm{Ca}^{2+}$ influx. (C) Effects of G-F4 on collagen-induced IP ${ }_{3} \mathrm{RI}$ phosphorylation. Measurement of $\left[\mathrm{Ca}^{2+}\right]_{\mathrm{i}}$ mobilization, influx, and Western blotting was described in "Materials and Methods" section. The data are expressed as the mean \pm standard deviation $(\mathrm{n}=4) .{ }^{*} p<0.05,{ }^{* *} p<0.01$ versus the collagen-stimulated human platelets. ${ }^{*} p<0.05$ versus the thapsigargininduced human platelets

(0.05 U/mL). Using a digital camera, pictures of fibrin clot were taken at $15 \mathrm{~min}$. The Image J Software (v1.46, National Institutes of Health, Bethesda, MD, USA) was used to calculate the clot area.

\section{Statistical analyses}

Experimental data are indicated as the mean \pm standard deviation included with the number of observations. Analysis of variance (ANOVA) was performed to determine significant differences among the groups and then further analyzed using the TukeyKramer method. SPSS 21.0.0.0 software (SPSS, Chicago, IL, USA) was used to perform statistical analysis. $p<0.05$ was considered as statistically significant.

\section{Results}

Effects of G-F4 on thrombin-induced human platelet aggregation Collagen at $2.5 \mu \mathrm{g} / \mathrm{mL}$ induces the optimum aggregation of human platelets, and in the present study, the aggregation rate of collagen induced platelets was $95.5 \%$ (Fig. 2A). However, platelets treated with G-F4 $(15,30,45$, and $60 \mu \mathrm{M})$ had aggregation rates that were significantly reduced $(20.7,44.5,88.0$, and $99.0 \%$, respectively) without cytotoxicity (Fig. 2D), indicating that collageninduced platelet aggregation was inhibited in a dose-dependent manner. DMSO $0.1 \%$ did not affect collagen-induced platelet 
aggregation. In addition, we tested ginsenoside F1 (G-F1) and ginsenoside F2 (G-F2), however, these compounds did not affect collagen-induced human platelet aggregation (Fig 2B, C).

\section{Effects of G-F4 on elevation of $\left[\mathrm{Ca}^{2+}\right]_{i}$ mobilization, calcium} influx, and $\mathrm{IP}_{\mathbf{3}} \mathrm{RI}$ phosphorylation

Due to the fact that $\left[\mathrm{Ca}^{2+}\right]_{\mathrm{i}}$ is essential for platelet activation, we investigated the effect of G-F4 on $\mathrm{Ca}^{2+}$ antagonistic activity. As shown in Fig. $3 \mathrm{~A},\left[\mathrm{Ca}^{2+}\right]_{\mathrm{i}}$ level was increased from 101.2 $\pm 0.6 \mathrm{nM}$ to $590.6 \pm 18.0 \mathrm{nM}$ by collagen $(2.5 \mu \mathrm{g} / \mathrm{mL})$. However, G-F4 dose (15 to $60 \mu \mathrm{M}$ )-dependently decreased collagen-elevated $\left[\mathrm{Ca}^{2+}\right]_{\mathrm{i}}$ level (Fig. 3A). The inhibition rate of G-F4 $(60 \mu \mathrm{M})$ was $75.2 \%$. Thapsigargin is an inhibitor of the sarco/endoplasmic reticulum $\mathrm{Ca}^{2+}$ ATPase, and is used to trigger $\mathrm{Ca}^{2+}$ influx from extracellular spaces. After adding $2 \mathrm{mM} \mathrm{CaCl}_{2}, 1 \mu \mathrm{M}$ of thapsigargin facilitated $\mathrm{Ca}^{2+}$ influx from $101.2 \pm 0.6 \mathrm{nM}$ (the basal level) to $930.9 \pm 38.0$ nM (Fig. 3B). However, only $60 \mathrm{iM}$ of G-F4 inhibited $\mathrm{Ca}^{2+}$ influx weakly (Fig. 3B). The inhibition rate of G-F4 $(60 \mu \mathrm{M})$ was $17.8 \%$.

Therefore, we expected that G-F4 affects calcium mobilization and evaluated the effect of phosphorylation of the calcium mobilization signaling molecule. As shown in Fig. 3C, G-F4 (15 to $60 \mu \mathrm{M})$ dose-dependently increased $\mathrm{IP}_{3} \mathrm{RI}\left(\mathrm{Ser}^{1756}\right)$ phosphorylation in collagen-induced human platelet aggregation. This shows that the decrease of intracellular calcium concentration by G-F4 resulted from $\mathrm{IP}_{3} \mathrm{RI}\left(\mathrm{Ser}^{1756}\right)$ phosphorylation.

\section{Effects of G-F4 on VASP-phosphorylation}

As G-F4 showed a dose-dependent inhibitory effect on collageninduced platelet aggregation (Fig. 2A), we further investigated the effect of G-F4 on VASP Ser $^{157}$ phosphorylation in collagenactivated platelets. G-F4 significantly increased VASP Ser ${ }^{157}$ phosphorylation (Fig. 4) in a dose-dependent manner. Conversely, G-F4 did not affect VASP Ser ${ }^{239}$ phosphorylation (data not shown) suggesting that G-F4 did not affect cGMP level.

\section{Effects of G-F4 on fibrinogen binding to $\alpha \mathrm{IIb} / \beta_{3}$}

Since VASP Ser ${ }^{157}$ phosphorylation on $\operatorname{Ser}^{157}$ inhibited fibrinogen binding and G-F4 increased VASP Ser ${ }^{157}$ phosphorylation (Fig. 4), we investigated the effect of G-F4 on fibrinogen binding to $\alpha \mathrm{IIb} /$ $\beta_{3}$ in human platelets. Collagen increased the binding of fibrinogen to $\alpha \mathrm{IIb} / \beta_{3}$ (Fig. $5 \mathrm{~A}-\mathrm{b}, 5 \mathrm{~B}$ ), with a rate of $90.8 \pm 0.5 \%$. However, G$\mathrm{F} 4$ attenuated the fibrinogen binding in a dose-dependent manner (Fig. 5A-d g, 5B). The inhibition rate of G-F4 $(60 \mu \mathrm{M})$ was $80.0 \%$.

\section{Effects of G-F4 on fibrin clot retraction}

Platelet agonists activate $\alpha \mathrm{Ilb} / \beta_{3}$ increasing the binding of fibrinogen to $\alpha \mathrm{Ilb} / \beta_{3}$. Eventually leading to the outside-in $\alpha \mathrm{IIb} / \beta_{3}$ signaling pathway and clot retraction. Thus, we investigated the effect of G-F4 on the retraction of thrombin-induced fibrin clots, which is an index of outside-in $\alpha \mathrm{IIb} / \beta_{3}$ signaling. Fig. $6 \mathrm{~A}$ shows thrombin stimulated fibrin clot formation and retraction. However, the thrombin-retracted fibrin clot was suppressed by G-F4 (45, 60

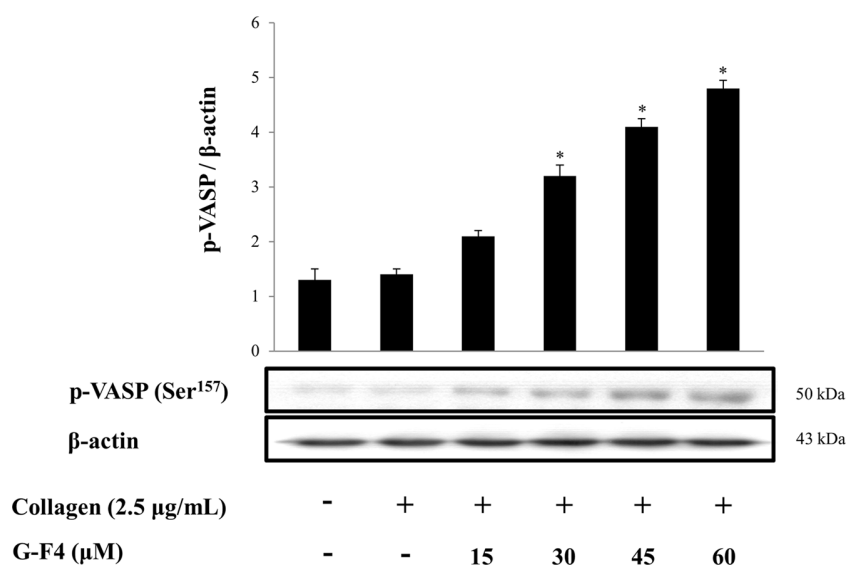

Fig. 4 Inhibitory effects of G-F4 on VASP phosphorylation. Western blotting was determined as described in "Materials and Methods" section. The data are expressed as the mean \pm standard deviation $(\mathrm{n}=4) .{ }^{*} p<0.05$, ${ }^{* *} p<0.01$ versus the collagen-stimulated human platelets

$\mu \mathrm{M})$, and these inhibitory degrees were $48.4,25.7 \%$, respectively as compared with that by thrombin (Fig. 6B).

\section{Discussion}

Our previous reports showed that phosphorylation of $\mathrm{IP}_{3} \mathrm{RI}$ $\left(\mathrm{Ser}^{1756}\right)$ and VASP $\left(\mathrm{Ser}^{157}\right)$ in human platelets is increased by the use of Korean red ginseng extract [17,18]. We also previously reported that the ginsenosides Rp1 show inhibitory effects through increased phosphorylation of VASP $\left(\mathrm{Ser}^{157}\right)$ [19]. Therefore, in the present study, we first examined the effect of G-F4 on cAMP/ PKA-dependent phosphorylation in collagen-activated human platelets. Phosphorylation of the $\mathrm{Ca}^{2+} /$ calmodulin-dependent myosin light chain is involved in granule secretion and platelet aggregation. This phosphorylation is due to an increase in $\left[\mathrm{Ca}^{2+}\right]_{\mathrm{i}}$ which is triggered by a number of agonists including thrombin, collagen, and ADP. G-F4 showed inhibitory effect on $\left[\mathrm{Ca}^{2+}\right]_{\mathrm{i} \text {; }}$ however, it did not affect thapsigargin-induced calcium influx which means that G-F4 has specific inhibitory effect on calcium mobilization from the endoplasmic reticulum without inhibition of calcium influx from extracellular space. This is clear evidence that the inhibition of $\left[\mathrm{Ca}^{2+}\right]_{i}$ by G-F4 resulted from the elevation of $\mathrm{IP}_{3} \mathrm{RI}\left(\mathrm{Ser}^{1756}\right)$ phosphorylation.

VASP $\operatorname{Ser}^{157}$ and $\operatorname{Ser}^{239}$ are phosphorylated by cAMP/PKA and cGMP/PKG, respectively [20, 21]. G-F4 elevated VASP $\left(\mathrm{Ser}^{157}\right.$ ) phosphorylation, but did not affect VASP $\left(\mathrm{Ser}^{239}\right)$ phosphorylation. Since VASP $\left(\mathrm{Ser}^{157}\right)$ and $\mathrm{IP}_{3} \mathrm{RI}\left(\mathrm{Ser}^{1756}\right)$ are substrates of PKA, our results suggest that G-F4 increased VASP $\left(\mathrm{Ser}^{157}\right)$ and $\mathrm{IP}_{3} \mathrm{RI}$ $\left(\mathrm{Ser}^{1756}\right)$ phosphorylation via cAMP/PKA dependent pathway in human platelets. Similar results were confirmed in our previous experiments. Ginsenoside Ro and Rg3 increased cAMP levels in human platelets, resulting in PKA-dependent phosphorylation and antiplatelet activity [22,23]. The results of G-F4 also showed the 

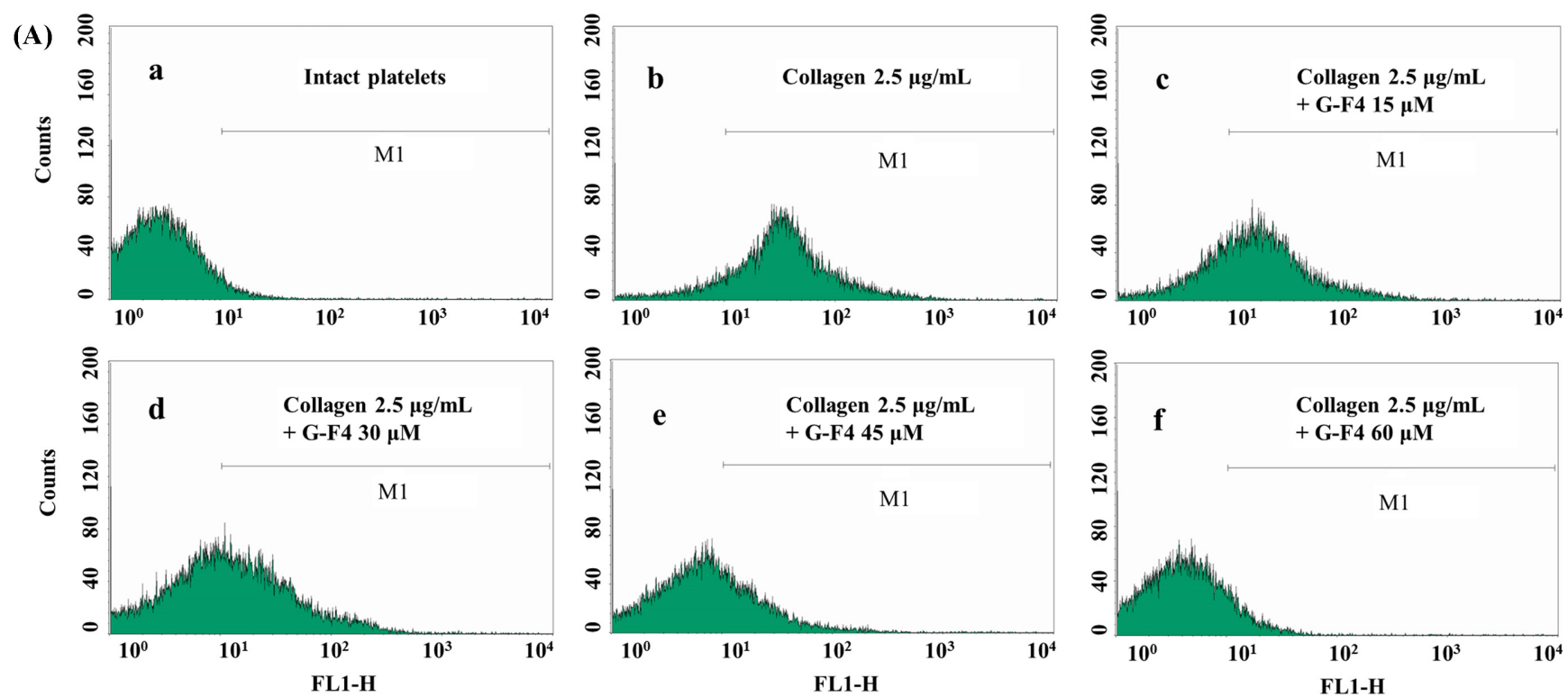

(B)

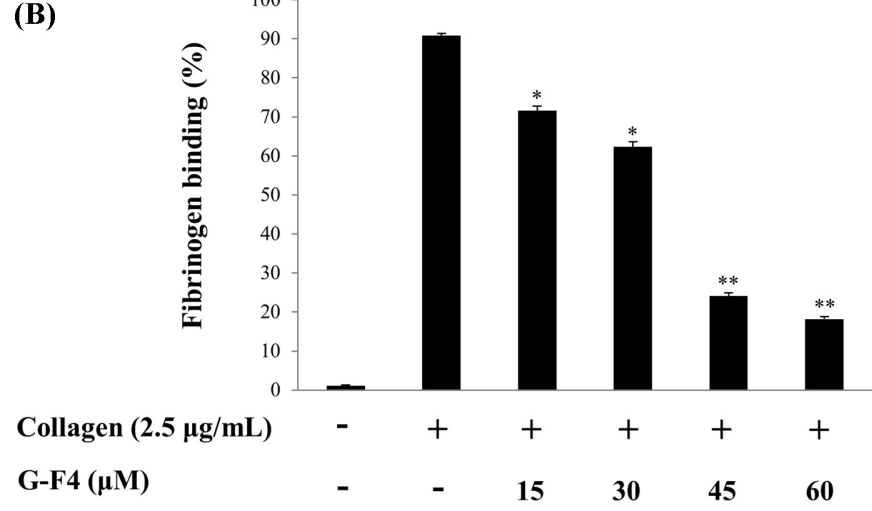

Fig. 5 Inhibitory effects of G-F4 on collagen-induced fibrinogen binding. (A) The flow cytometry histograms on fibrinogen binding. a, Intact platelets (base); b, collagen $(2.5 \mu \mathrm{g} / \mathrm{mL})$; c , collagen $(2.5 \mu \mathrm{g} / \mathrm{mL})+\mathrm{G}-\mathrm{F} 4$ $(15 \mu \mathrm{M}) ; \mathrm{d}$, collagen $(2.5 \mu \mathrm{g} / \mathrm{mL})+\mathrm{G}-\mathrm{F} 4(30 \mu \mathrm{M})$; e, collagen $(2.5 \mu \mathrm{g} /$ $\mathrm{mL})+\mathrm{G}-\mathrm{F} 4(45 \mu \mathrm{M})$; f, collagen $(2.5 \mu \mathrm{g} / \mathrm{mL})+\mathrm{G}-\mathrm{F} 4(60 \mu \mathrm{M})$. (B) Effects of G-F4 on collagen-induced fibrinogen binding (\%). Measurement of fibrinogen binding was described in "Materials and Methods section". The data are expressed as the mean \pm standard deviation $(\mathrm{n}=4) .{ }^{*} p<0.05$, $* * p<0.01$ versus the collagen-stimulated human platelets

same inhibition pattern. G-F4 inhibited collagen-induced fibrinogen binding to $\alpha \mathrm{IIb} / \beta 3$ and this result is mediated by increased VASP $\left(\mathrm{Ser}^{157}\right)$ phosphorylation.

Calpain is a calcium-dependent cysteine protease, which consists of calpain-1 and calpain-2 in platelets. Various calpain substrates have been identified in platelets such as Src, Syk, FAK, SHP-1, PTP1B, and inositol-4-phosphatase. These substrates consist of protein kinase or phosphatase; thus, calpain may regulate the balance between kinase and phosphatase activities [24]. Particularly, calpain has been implicated in the modulation of $\alpha \mathrm{IIb} / \beta 3$ mediated outside-in signaling pathway. The platelets from calpain1 knockout mice are defective in platelet aggregation in response to a number of agonists such as ADP, thrombin, and collagen [25]. Integrin $\alpha \mathrm{IIb} / \beta 3$-mediated signaling generally results in the modification of the platelet cytoskeleton, therefore affecting platelet spreading and clot retraction. The clot retraction is the most important step during the repair of the damaged portion of the blood vessel. The damaged blood vessel accumulates activated platelets which develop into a fibrin-platelet meshwork. The clot formation that seals off the damaged vessel starts to retract during a time frame of around 30 to 60 minutes and pulls the cut edges together. The interaction between $\alpha \mathrm{IIb} / \beta 3$ and fibrin is a key role for the clot formation and the $\alpha \mathrm{IIb} / \beta 3$ inhibitors strongly suppress the clot retraction [26]. Our results showed that G-F4 decreased $\left[\mathrm{Ca}^{2+}\right]_{\mathrm{i}}$ through elevation of $\mathrm{IP}_{3} \mathrm{RI}\left(\mathrm{Ser}^{1756}\right)$ phosphorylation and inhibited $\left[\mathrm{Ca}^{2+}\right]_{\mathrm{i}}$ may be influenced by calcium-dependent cysteine protease. Therefore, G-F4 suppressed collagen-induced fibrinogen binding to $\alpha \mathrm{IIb} / \beta 3$ and thrombin-stimulated clot retraction together with VASP $\left(\mathrm{Ser}^{157}\right)$ phosphorylation.

We previously reported that synthetic ginsenoside compounds Rp1 (G-Rp1), Rp3 (G-Rp3), Rp4 (G-Rp4), and natural compounds from Panax ginseng 20(S)-Rg3 (G-Rg3), Ro (G-Ro), have antiplatelet effects [17]. G-Rp1 has two glucose residues connected at carbon-3 position (Fig. 7A), and $20 \mu \mathrm{M}$ of G-Rp1 fully inhibited rat platelet aggregation. G-Rp3 also has two glucose residues at carbon-6 position (Fig. 7B), and $50 \mu \mathrm{M}$ of Rp3 shows maximal inhibitory effect on rat and human platelets. G-Rp4 has one glucose residue at carbon-6 position (Fig. 7C) which is structurally similar with G-Rp3. $50 \mu \mathrm{M}$ of G-Rp3 showed inhibitory effect in rat platelets. In addition, $300 \mu \mathrm{M}$ of G-Rg3 (Fig. 7D) and G-Ro 
(A)

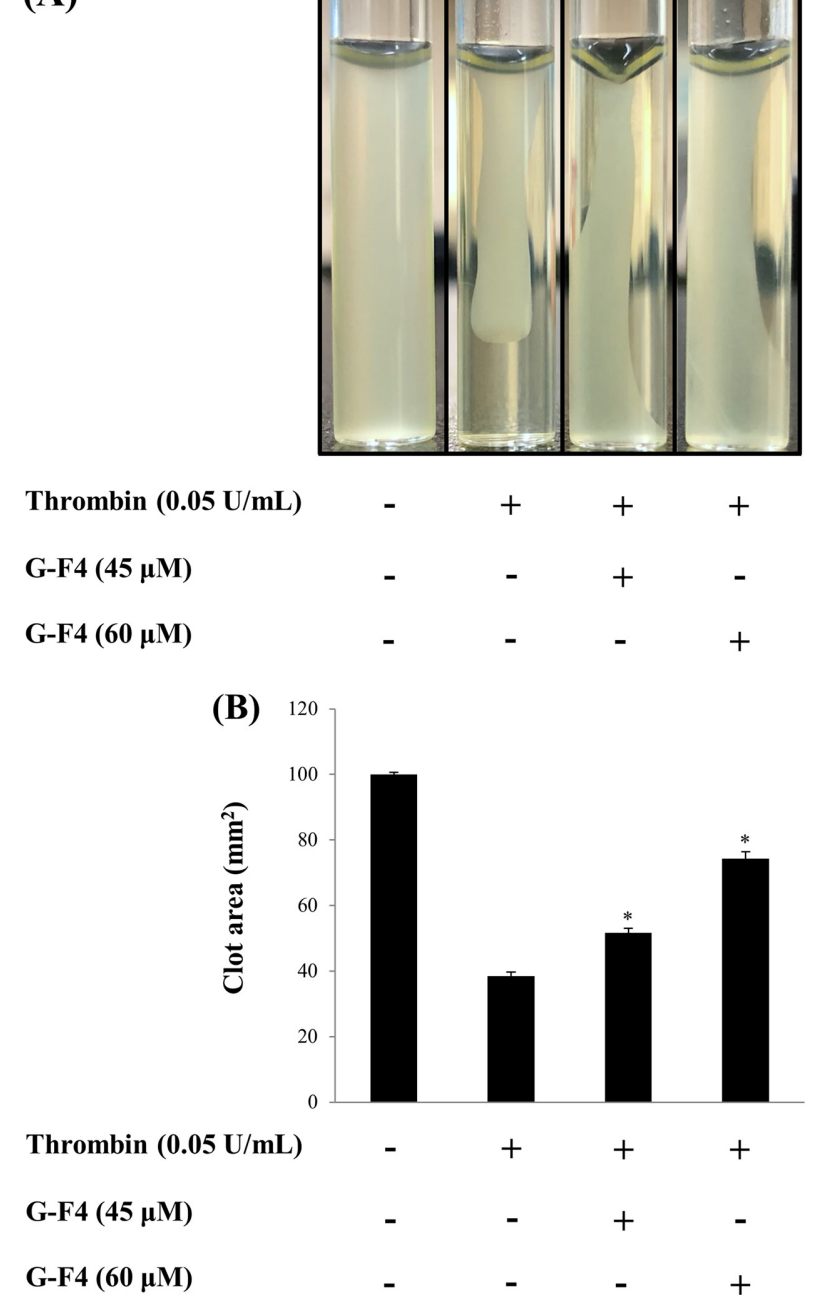

Fig. 6 Inhibitory effects of G-F4 on fibrin clot retraction. (A) Effects of G-F4 on thrombin-retracted fibrin clot photographs (B) Effects of G-F4 on thrombin-retracted fibrin clot area. Quantification of fibrin clot retraction was described in "Materials and Methods" section. The data are expressed as the mean \pm standard deviation $(\mathrm{n}=4) .{ }^{*} p<0.05$ versus the thrombin-stimulated platelets

(Fig. 7E) inhibited thrombin-induced human platelets. The structure of G-F4 is similar with G-Rp3 and G-Rp4 which has sugar residue at carbon-6 position. However, G-F1 do not have any sugar residue at carbon- 3 and carbon- 6 position, and G-F2 is connected one glucose residue at carbon- 3 position, these did not inhibit on collagen-induced human platelets. Considering these structural differences, it is expected that the structure of ginsenoside, which have any sugar residue on carbon- 6 position or two or more sugars on carbon-3 position, may be related to the specific ligands or integrins of platelets. In order to confirm this accurately, it is necessary to perform molecular docking analysis in the future.

In conclusion, we found G-F4 inhibited calcium mobilization, fibrinogen-binding to $\alpha \mathrm{IIb} / \beta_{3}$, and clot retraction, which are mediated by the phosphorylation of $\mathrm{IP}_{3} \mathrm{RI}\left(\mathrm{Ser}^{1756}\right)$ and VASP
$\left(\mathrm{Ser}^{157}\right)$. Therefore, we suggest that G-F4 is a novel compound for prevention of thrombosis and other platelet-mediated cardiovascular diseases by inhibiting intracellular calcium mobilization and $\alpha \mathrm{IIb} /$ $\beta_{3}$ activation.

Acknowledgments Funding for this paper was provided by Namseoul University.

Conflict of interest The authors declare no conflict of interest.

\section{References}

1. Jackson SP (2011) Arterial thrombosis-insidious, unpredictable and deadly. Nature medicine 17: 1423-1436

2. Barrett NE, Holbrook L, Jones S, Kaiser WJ, Moraes LA, Rana R, Gibbins JM (2008) Future innovations in anti-platelet therapies. Brit J Pharmacol 154: 918-939

3. Payrastre B, Missy K, Trumel C, Bodin S, Plantavid M, Chap H (2000) The integrin alpha IIb/beta 3 in human platelet signal transduction. Biochem Pharmacol 60: 1069-1074

4. Phillips DR, Nannizzi-Alaimo L, Prasad KS (2001) Beta3 tyrosine phosphorylation in alphaIIbbeta3 (platelet membrane GP IIb-IIIa) outside-in integrin signaling. Thromb Haemost 86: 246-258

5. Schwartz SM, Heimark RL, Majesky MW (1990) Developmental mechanisms underlying pathology of arteries. Physiol Rev 70: 11771209

6. Varga-Szabo D, Braun A, Nieswandt B (2009) Calcium signaling in platelets. J Thromb Haemost 7: 1057-1066

7. Schwarz UR, Walter U, Eigenthaler M (2001) Taming platelets with cyclic nucleotides. Biochem Pharmacol 62:1153-1161

8. Cavallini L, Coassin M, Borean A, Alexandre A (1996) Prostacyclin and sodium nitroprusside inhibit the activity of the platelet inositol 1,4,5trisphosphate receptor and promote its phosphorylation. J Biol Chem 271: 5545-5551

9. Quinton TM, Dean WL (1992) Cyclic AMP-dependent phosphorylation of the inositol-1,4,5-trisphosphate receptor inhibits $\mathrm{Ca}^{2+}$ release from platelet membranes. Biochemical and Biochem Biophys Res Commun 184: 893-899

10. Laurent V, Loisel TP, Harbeck B, Wehman A, Gröbe L, Jockusch BM, Wehland J, Gertler FB, Carlier MF (1999) Role of proteins of the Ena/ VASP family in actin-based motility of Listeria monocytogenes. J Cell Biol 144: 1245-1258

11. Sudo T, Ito H, Kimura Y (2003) Phosphorylation of the vasodilatorstimulated phosphoprotein (VASP) by the anti-platelet drug, cilostazol, in platelets. Platelets 14: 381-390

12. Ha YW, Lim SS, Ha IJ, Na YC, Seo JJ, Shin H, Kim YS (2007) Preparative isolation of four ginsenosides from Korean red ginseng (steam-treated Panax ginseng CA Meyer), by high-speed counter-current chromatography coupled with evaporative light scattering detection. J Chromatogr A 1151: 37-44

13. Park JD, Rhee DK, Lee YH (2005) Biological activities and chemistry of saponins from Panax ginseng CA Meyer. Phytochem Rev 4: 159-175

14. Chen B, Shen YP, Zhang DF, Cheng J, Jia XB (2013) The apoptosisinducing effect of ginsenoside F4 from steamed notoginseng on human lymphocytoma JK cells. Nat Prod Res 27: 2351-2354

15. Lee JH, Lim H, Shehzad O, Kim YS, Kim HP (2014) Ginsenosides from Korean red ginseng inhibit matrix metalloproteinase-13 expression in articular chondrocytes and prevent cartilage degradation. Eur J Pharmacol 724: $145-151$

16. Grynkiewicz G, Poenie M, Tsien RY (1985) A new generation of $\mathrm{Ca}^{2+}$ indicators with greatly improved fluorescence properties. J Biol Chem 


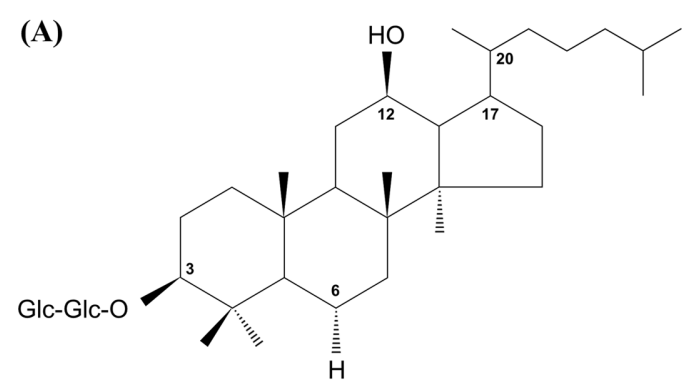

Ginsenoside Rp1<smiles>CC(C)CCC[C@@H](C)C1CC[C@]2(C)C1[C@@H](O)CC1[C@@]3(C)CC[C@@H](O)C(C)(C)C3[C@@H](OC(C)C)C[C@]12C</smiles>

Ginsenoside Rp4

(E)

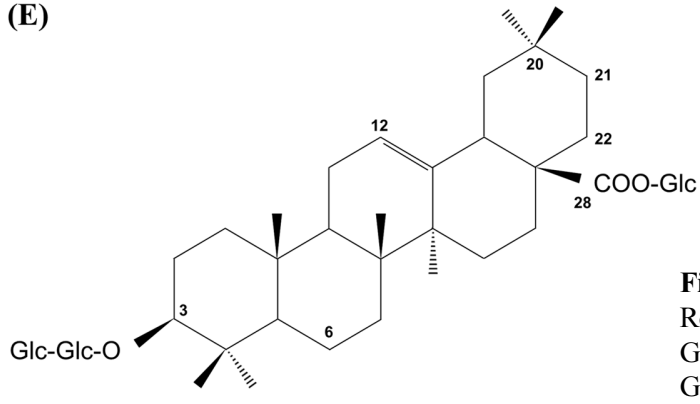

Ginsenoside Ro

260: $3440-3450$

17. Shin JH, Kwon HW, Cho HJ, Rhee MH, Park HJ (2015) Inhibitory effects of total saponin from Korean red ginseng on $\left[\mathrm{Ca}^{2+}\right]_{i}$ mobilization through phosphorylation of cyclic adenosine monophosphate-dependent protein kinase catalytic subunit and inositol 1, 4, 5-trisphosphate receptor type I in human platelets. J Ginseng Res 39: 354-364

18. Kwon HW, Shin JH, Cho HJ, Rhee MH, Park HJ (2016) Total saponin from Korean Red Ginseng inhibits binding of adhesive proteins to glycoprotein IIb/IIIa via phosphorylation of VASP (Ser157) and dephosphorylation of PI3K and Akt. J Ginseng Res 40: 76-85

19. Irfan M, Jeong DH, Kwon HW, Shin JH, Park SJ, Kwak D, Rhee MH (2018) Ginsenoside-Rp3 inhibits platelet activation and thrombus formation by regulating MAPK and cyclic nucleotide signaling. Vasc Pharmacol 109: 45-55

20. Smolenski A, Bachmann C, Reinhard K, Hönig-Liedl P, Jarchau T, Hoschuetzky H, Walter U (1998) Analysis and regulation of vasodilatorstimulated phosphoprotein serine239 phosphorylation in vitro and in intact cells using a phosphor specific monoclonal antibody. J Biol Chem 273: 20029-20035

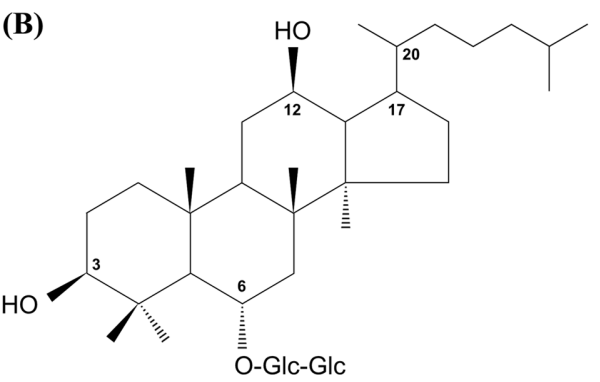

(D)

Glc-Glc-O

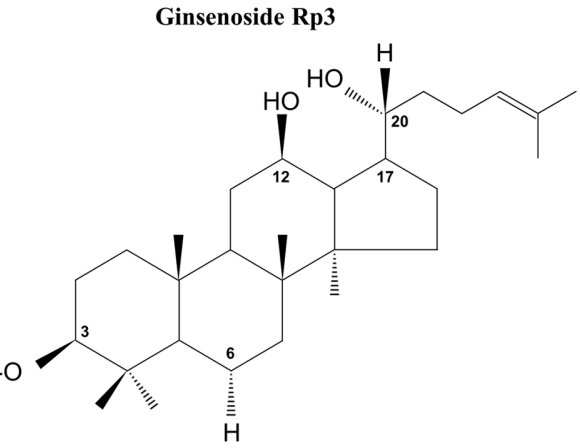

20(S)-Ginsenoside Rg3

Fig. 7 Chemical structure of ginsenoside Rp1, Rp3, Rp4, 20(S)-Rg3 and Ro. (A) Ginsenoside Rp1, two glucose residues at carbon-3 position. (B) Ginsenoside Rp3, two glucose residues at carbon-6 position. (C) Ginsenoside Rp4, one glucose residue at carbon-3 position. (D) 20(S)ginsenoside $\mathrm{Rg} 3$, two glucose residues at carbon-3 position. (E) Ginsenoside Ro, two glucose residues at carbon-3 position

21. Barragan P, Bouvier JL, Roquebert PO, Macaluso G, Commeau P, Comet B, Eigenthaler M (2003) Resistance to thienopyridines: Clinical detection of coronary stent thrombosis by monitoring of vasodilatorstimulated phosphoprotein phosphorylation. Catheter Cardiovasc Interv 59: 295-302

22. Shin JH, Kwon HW, Cho HJ, Rhee MH, Park HJ (2016) Vasodilatorstimulated phosphoprotein-phosphorylation by ginsenoside Ro inhibits fibrinogen binding to $\alpha \mathrm{IIb} / \beta 3$ in thrombin-induced human platelets. J Ginseng Res 40: 359-365

23. Kwon HW (2018) 20 (S)-ginsenoside Rg3 inhibits glycoprotein IIb/IIIa activation in human platelets. J Appl Biol. Chem 61: 257-265

24. Kuchay SM, Chishti AH (2007) Calpain-mediated regulation of platelet signaling pathways. Curr Opin Hematol 14: 249-254

25. Azam M, Andrabi SS, Sahr KE, Kamath L, Kuliopulos A, Chishti AH (2001) Disruption of the mouse $\mu$-calpain gene reveals an essential role in platelet function. Mol Cell Biol 21: 2213-2220

26. Topol EJ, Byzova TV, Plow EF (1999) Platelet GPIIb-IIIa blockers. The Lancet 353: 227-231 